\title{
Energy from Combustion of Rice Straw: Status and Challenges to China
}

\author{
Zhiqiang Liu*, Aixiang Xu, Tenglv Zhao \\ School of Energy Science and Engineering, Central South University, Changsha, China \\ E-mail: liuzq@csu.edu.cn \\ Received January 20, 2011; revised February 22, 2011; accepted March 10, 2011
}

\begin{abstract}
As the biggest agricultural country, China has an abundant rice straw energy resource. The characteristics of typical china rice straws are presented as high moisture contents, high volatile contents, high ash contents and low bulk density. At present, rice straw is mainly used as fuel, feedstuff, fertilizer and industrial raw material. With improved living conditions in rural areas, farmers tend to rely more on commercial fuel, which leads to even more open field burning of rice straw, and brings air pollutions and potential energy waste as well. The Chinese government is studying relevant policies on acceleration of comprehensive utilization of rice straw with the goal of utilization rate exceeding $80 \%$ in 2015 . In this paper, focus is on the combustion of rice straw to extract energy, and related challenges face to china is put forward in this paper also.
\end{abstract}

Keywords: Rice Straws, Combustion, Pollutions, Open-Field burning, Grate-Firing

\section{Introduction}

As the biggest agricultural country, China has abundant biomass energy resource which mainly comes from crop residues, firewood, forest wood residues and organic refuses. About 0.75 billion tons of agricultural residues are produced in 2010 [1] and this is equivalent to about 12,000 trillion $\mathrm{kJ}$ of energy. Of the biomass, the crop residues is the biggest biomass resource, covering about $52 \%$ of the total biomass resource in China and the rice straw biomass is about $62 \%$ of the total crop residues [1] [2]. At present, crop straws are mainly used as fuel, feedstuff, fertilizer and industrial raw material. According to Resource Saving and Environmental Protection Bureau of National Development and Reform Commission, to promote comprehensive utilization of straw resources and realize straw commercialization and resource utilization is important to resource saving, pollution abatement, farmer incomes increase and acceleration of resource-saving and environmental-protection society constructions. The State is studying relevant policies on acceleration of comprehensive utilization of crop straws. The comprehensive utilization rate of straw resources is expected to exceed $80 \%$ in 2015 [1].

Rice is grown in most China regions and the primary rice-harvesting season is from June to October up to different regions and climates. The collection of straw is shortly after rice harvest but is dependent on soil moisture conditions and straw moisture. In the absence of rain, the straw moisture can normally be reduced low enough to allow straw harvest and storage within 1 - 2 days after the grain harvest. For every tone of grain harvested, about 1.35 tonnes of rice straw remain in the field [3]. Rice straw production in China 2010 was 1.9 million tones at $15 \%$ moisture [1]. The only method commonly used to harvest and handle rice straw is baling, and even this has been done only on a limited basis because of lack of demand for the straw.

Conversion of rice straw to energy is undertaken using two main processing technologies: thermo-chemical and bio-chemical/biological. Within thermo-chemical conversion four processing options are available: combustion, pyrolysis/gasification and liquefaction. Bio-chemical conversion encompasses two processing options: digestion and fermentation [4,5]. Different from other discussions, the paper is focusing on the combustion of rice straw in china. Status on the combustion application of rice straws are reviewed and related challenges including the harvesting issues, process and system considerations, technical improvement and policy support face to China are presented. 


\section{Characteristics of Rice Straw}

Rice straw from different regions has different characteristics. Table 1 and Table 2 show the proximate and the ultimate analyses of a typical China rice straw [6]. More detail analysis is following.

\subsection{Moisture Content}

The moisture contents of the rice straw are between $10 \%$ $20 \%$ which harvested in summer will be lower than that of rice harvested in fall. For rice straw having high moisture contents, some problems may be countered during firing. High moisture contents can lead to poor ignition, reduce the combustion temperature, which in turn hinders the combustion of the reaction products and consequently affects the quality of combustion [7]. Further, a large quantity of flue gas is formed during the combustion of high moisture content fuels which eventually leads to large dimensions of the equipment for flue gas treatment.

\subsection{Bulk Density}

The rice straw has low bulk densities. For example, the bulk density of chopped straw is $50-120 \mathrm{~kg} / \mathrm{m}^{3}$ [3]. It is very low compared with the bulk densities of coals, which are in the range of $560-600 \mathrm{~kg} / \mathrm{m}^{3}$ for brown coals and between 800 and $900 \mathrm{~kg} / \mathrm{m}^{3}$ for bituminous coal. The low densities of the rice straw complicate their processing, transportation, storage and firing.

\subsection{Ash Content}

Rice straw differs from most crop residues in its high content of silicon dioxide $\left(\mathrm{SiO}_{2}\right)$. Ash content on a dry weight basis ranges from $0.1 \%$ to $0.7 \%$, varying according to the state of conservation of the straw after harvest. The ash generally contains $75 \% \mathrm{SiO}_{2}, 10 \% \mathrm{~K}_{2} \mathrm{O}, 3 \%$ $\mathrm{P}_{2} \mathrm{O}_{5}, 2 \% \mathrm{Fe}_{2} \mathrm{O}_{3}, 1.5 \% \mathrm{CaO}$, and small amounts of $\mathrm{Mg}, \mathrm{S}$, and $\mathrm{Na}$ [8]. Table 3 indicates a typical chemical composition of rice straw, shown as a weight percentage on a dry basis.

\subsection{Volatile Matter}

Compared with coals and other agricultural residues, rice straw is characterized by higher contents of volatile matter up to $85 \%$ dry basis. This indicates that the rice straw is easier to ignite and to burn, although the combustion is expected to be rapid and difficult to control. Experience showed that the high volatile matter contents significantly affect the combustion process [7]. The implication of this is that the design and operation principles normally adopted for coal combustion systems, may not be applied for the combustion of rice straw. Care must be taken to achieve complete combustion of the volatiles to ensure higher combustion efficiency and low emissions of $\mathrm{CO}$, hydrocarbons and $\mathrm{PAH}$.

\subsection{Pollutant Emissions}

The other important properties related to the combustion of rice straw are the contents of sulphur, nitrogen, chlorine etc. which are expected to lead to the formation of gaseous pollutants such as $\mathrm{SO}_{2}, \mathrm{NO}_{\mathrm{x}}, \mathrm{N}_{2} \mathrm{O}$ and $\mathrm{HCl}$ and, to some extent, dioxins and furans [7,9]. On the other hand, rice straw burning activities are important sources of aerosol particles, affecting regional air quality and the radiation budget of the earth [10].

Table 1. The proximate analyses of typical china rice straw.

\begin{tabular}{ccccc}
\hline & Moisture, wt $\%$ & & \multicolumn{2}{c}{ Proximate analysis (wt\%, dry basis) } \\
\cline { 3 - 5 } & $10-20$ & Volatiles & Fixed carbon & Ash \\
\hline Rice Straw & $75-85$ & $15-25$ & $0.1-0.7$ & HHV MJ/kg (DAF) \\
\hline
\end{tabular}

Table 2 . The ultimate analyses of typical china rice straw.

\begin{tabular}{ccccccccc}
\hline & \multicolumn{1}{c}{ Ultimate analyses (wt\%, dry basis) } \\
\cline { 2 - 6 } & $\mathrm{C}$ & $\mathrm{H}$ & $\mathrm{O}$ & $\mathrm{N}$ & $\mathrm{S}$ & $\mathrm{Cl}$ \\
\hline Rice Straw & $47-52$ & $6.1-6.3$ & $38-45$ & $<0.2$ & $<0.1$ & $<0.02$ & $0.036-0.055$ & \\
\hline
\end{tabular}

Table 3. The chemical composition of rice straw ash.

\begin{tabular}{|c|c|c|c|c|c|c|c|c|c|c|c|}
\hline Oxide( $\%$ ash $)$ & $\mathrm{SiO}_{2}$ & $\mathrm{Al}_{2} \mathrm{O}_{3}$ & $\mathrm{TiO}_{2}$ & $\mathrm{Fe}_{2} \mathrm{O}_{3}$ & $\mathrm{CaO}$ & $\mathrm{MgO}$ & $\mathrm{Na}_{2} \mathrm{O}$ & $\mathrm{K}_{2} \mathrm{O}$ & $\mathrm{SO}_{3}$ & $\mathrm{P}_{2} \mathrm{O}_{5}$ & Und $^{*}$ \\
\hline Rice Straw & 75 & 1.4 & 0.02 & 2.0 & 1.5 & 1.9 & 1.9 & 10.0 & 0.9 & 2.7 & 3.6 \\
\hline
\end{tabular}

*Undetermined, may consist primarily of chlorine and carbonates. 


\section{Current status of Rice Straw to Energy in China}

Traditionally, biomass is a major energy source in China, especially in its rural areas. Crop residues are main sources of biomass and mainly used as fuels for cooking food and/or warming room by the way of direct burning. In $1970 \mathrm{~s}$, there was a serious shortage of energy occurred in Chinese rural areas. In order to resolve this problem, China government put the development of biomass energy utilization technology from 1981. Since that time, China had begun to develop its biomass resources and energy conversion technology. Up to 1990 , 5 million sets of household biogas digesters had been built and operated, and a great amount of saving-fuel stoves had been used by 110 million of rural families. Rice straw acts as an important role in this period but still is in its infancy.

Since 1991, the development of rural economy has brought a new problem that rural residents have begun to disuse their traditional biomass fuel, but prefer to use convenient and clean fuels, such as coal and liquefied natural gas, because burning biomass fuels directly is less efficient, labored and too dirty. Thus, rice straw was usually disposed of by open-field burning because it is a cheap disposal method and it also helps avoid propagating disease. More important is that most growers want to burn rice straw as soon as possible, if the weather permits, to allow for fall ground preparation.

Burning is often delayed by inclement weather. Although open-field burning is a convenient option, it produces visible smoke. This practice has been studied extensively and data on actual emissions from rice straw burning are shown in Table 4 [3]. Furthermore, silica emissions, which are not specifically monitored, are of concern since they can pose a health hazard.

For these reasons, China has paid more attention on developing new technologies to convert rice straw into convenient and clean energy products, such as low or middle energy gas fuel, biogas, briquetting fuel and liquid fuel, in the period of the11th Five Year Plan (20052010). By hard works on biomass energy in this period, an integrated management, development and research system net has been set up between the government, institutes/ universities, manufacturers and users in China. The system net has been and will be operated to speed the development and popularization of the technology in

Table 4. Emissions from rice straw burning.

\begin{tabular}{cccccc}
\hline & PM 10 & VOC & $\mathrm{NO}_{x}$ & $\mathrm{SO}_{\mathrm{x}}$ & $\mathrm{CO}$ \\
\hline Emissions in $\mathrm{kg} \cdot \mathrm{ha}^{-1}$ & 23.3 & 5.8 & 19.0 & 4.1 & 211.0 \\
Emissions in $\mathrm{kg} \cdot \mathrm{t}^{-1}$ straw & 3.7 & 1.0 & 3.1 & 0.7 & 34.7 \\
\hline
\end{tabular}

the country. Among these technologies, combustion of rice straw is very important one. But there are many challenges because of the characteristics of rice straw.

\section{Challenges to Combustion of Rice Straw in China}

The characteristics of typical china rice straws are presented as high moisture contents, high volatile contents, high ash contents and low bulk density. Therefore, there are many challenges to the combustion of rice straw. The main considerations include harvesting, process and system, combustion technology and policy.

\subsection{General Harvesting Issues}

Rice straw collection requires the consideration of several constraints as described below [3].

\subsubsection{Disease and Pests}

Burning the rice straw in the field act as a common way to destroy the stem rot sclerotic. For the sake of energy transmission, the rice straw should be colleted, transported and stored, and the disease and pets will propagate with this chain. Conceptual method should be adopted to distinguish them from the energy transmission chain.

\subsubsection{Timeliness of Operation}

The timeliness of straw collection is a concern of many growers. To be successful, the collection system needs to operate within the variable time constraints imposed by the weather and growers' cultivation practices for their primary product.

\subsubsection{Soil Nutrients}

A potential hazard of utilizing rice straw is field nutrient depletion [11]. Soil analysis appears to indicate that soil nutrients are being depleted and will require the addition of certain nutrients to compensate for this loss.

\subsubsection{Usability of Machinery}

The feasibility of mechanical harvesting depends on the carrying or bearing capacity of the soil. Due to long and heavy rain, the soil often turns muddy thereby limiting the use of machinery. The problem is particularly significant in those areas where rice is harvested in autumn when evaporation is poor, and sunshine is limited [3]. The final destination of the straw may also influence the choice of baling technique. All machinery above a certain weight is excluded due to the limited load-bearing capacity of the rice fields, and the absolute need to leave the leveling of the ground undisturbed. 


\subsubsection{Grower Attitudes}

In rice straw collection, it is important to properly interface the collection system with the growers' own operations. Farmers do not tolerate any interference with harvesting operations and do not change their operations to facilitate straw harvesting without economical motivations [12]. New regulations should provide farmers with an economic incentive to cooperate with rice straw collection.

\subsection{Process and System Considerations}

\subsubsection{System Considerations}

Systems needed for the collection, processing, and transportation of rice straw have been developed in China recently [1]. However, for the reason of lacking sufficient infrastructure and available machinery for working on wet, muddy ground currently, it will provide rice straw to off-farm use. The operating capacity of the different harvesting systems using baling would depend on the amount of the straw in the field, ground conditions for machinery use, and the field size; the technical characteristics of the machinery would be less of an issue. The nature of the rice straw creates high wear and maintenance for processing equipment, resulting in processing cost increases over that of less harsh materials.

\subsubsection{Drying}

At harvest, the rice straw has a water content of $60 \%$ $70 \%$ (weight basis); however, it is necessary to wait until this drops below $25 \%$ before harvesting and storage can commence. This drying must be left to occur naturally, in view of the low intrinsic value of the product. It should be noted that if the moisture content of baled straw is above $25 \%$, fermentation begins, with a loss of dry matter and resultant worsening of quality; spontaneous combustion in the stacks is also a possibility [3]. Transporting moist straw is more expensive when the costs are expressed on a dry weight basis.

\subsubsection{Densification of the Straw}

Utilization of the straw off-farm implies transporting the straw from the separation sites to a user facility. Transportation of loose straw is expensive, and densification of the straw is most probably necessary. Compaction to a bulk density of over $227 \mathrm{~kg} / \mathrm{m}^{3}$ would result in a load of over 20 tons in a container with approximately $84 \mathrm{~m}^{3}$ capacity [3]. This capacity is the size of a commercial container used for transporting municipal solid waste. Bulk rice straw of higher densities than $227 \mathrm{~kg} / \mathrm{m}^{3}$ can be easily used.

\subsubsection{Logistic Cost and Storage}

The logistics of the fuel supply have a large impact on the economy of a biomass utilization facility, especially for low density biomass fuels like rice straw. Studies have shown that the costs for all logistics operations vary from a minimum of $18.75 \mathrm{USD} / \mathrm{t}$ for small rectangular bales in the Northern region of Thailand to maximum 19.89 USD/t for large rectangular bales in the Northeastern region [13]. The situation is same as China.

The requirements for storage of rice straw vary with the method used for collecting the straw. The storage site may need to be hard surfaced to insure access during wet periods of the year. Storage space of these magnitudes can probably be provided. The economics of collection will have some influence on the availability of storage space for straw. Another storage issue that will need attention is the effect of high winds on large exposed piles of loose straw.

\subsection{Technical Improvement}

\subsubsection{Development of Combustion Systems}

The design of the appropriate equipment depends on the type, the amount and the characteristics of the rice straw and the desired energy form (heat, steam, electric power) which in turn depends on the respective energy use. Further design aspects concern the relationship of the rice straw combustion system to other systems in the same plant (i.e. independent or integrated operation), the disposal methods needed for the residues and environmental factors. For the design of efficient large-scale rice straw combustion systems a lot of parameters have to be taken into account. These parameters are e.g. the mean value and the variability of moisture, the volatile matter content, ash content, ash composition, agglomeration characteristics and the energy content of the fuel. Further, the furnace design will depend on the emission limits that have to be kept. Combustors for agricultural waste fuels are predominantly grate-fired systems, suspension burners or fluidized bed systems [7].

Grate-firing systems have some specific advantages which include being able to handle fuels with high moisture contents up to $65 \mathrm{wt} \%$ water, low investment costs and also low operating costs. Further advantages are the good burnout of fly ash particles and the low dust load in the flue gas. Fluidized bed combustors are used worldwide to combust both coal and biomass. The inherent advantages of fluidized beds make them an attractive option for the combustion of agricultural residues. The $\mathrm{NO}_{\mathrm{x}}$ emission control by air staging in fluidized bed reactors has been thoroughly investigated and is working well. The combustion intensity in fluidized bed combustors is higher than that in grate-fired systems. To combust agricultural residues in suspension burners, it is required that they are dry (e.g. less then $15 \mathrm{wt} \%$ moisture contents) and finely divided (e.g. particle size, $2 \mathrm{~mm}$ ). 


\subsubsection{Problems of the Low Points of Ashes}

A major problem observed during the combustion of rice straw was ash sintering and bed agglomeration. This is due to the low melting temperature of the ash, which is attributed to the high contents of $\mathrm{K}_{2} \mathrm{O}$ of the rice straw [7]. Special equipment is required for the solution of ash sintering and bed agglomeration.

\subsubsection{Solving Secondary Pollution Problems}

Critically related to the properties of rice straw are pollutant emissions generated by combustion. Primary pollutants formed are particulate matter (PM), CO, $\mathrm{HC}$, oxides of nitrogen $\left(\mathrm{NO}_{\mathrm{x}}\right)$ and oxides of sulfur $\left(\mathrm{SO}_{\mathrm{x}}\right)$.

PM includes soot, ash, condensed fumes tars/oils, and sorbed materials including VOC and PAH. Most combustion generated particles are less than $1 \mu \mathrm{m}$ aerodynamic particle size. Respirable particles of $10 \mu \mathrm{m}$ or smaller PM10 are breathing hazards, as they are retained deep in the alveoli of the lung. Mechanically generated particulate matter including carry-over fuel fines and ash particles tend to be fairly large compared to combustion aerosols. Biogenic silica is partly released as fibrous particulate matter which has become of concern recently for lung disease.

Emissions of oxides of nitrogen and sulfur arise predominantly from nitrogen and sulfur in the fuel. Most combustors operate at temperatures low enough that thermal $\mathrm{NO}_{\mathrm{x}}$ contributes only a small fraction of the total. $\mathrm{NO}_{\mathrm{x}}$ Combination with $\mathrm{HC}$ photochemically leads to the formation of ozone, which are a lung and eye irritant and a major problem in urban environments. Ozone is also damaging to plants. Sulfur oxides are respiratory irritants, and their effects are enhanced in the presence of PM due to transport deep within the lung. Both nitrogen and sulfur oxides participate in reactions leading to acid rain.

\subsection{Policy Support}

In recently years, China has made a significant progress in the exploitation and use of renewable resources. Since the late 1970s, Chinese government has stipulated some principles and policies to encourage and develop renewable energy [14-15]. All of this include Laws, regulations, Economic encouragement policies, Industrialized support policies, Technical research and development policies, Government renewable resources model projects, etc. For extraction energy from combustion of rice straw, some measures should be enforced including enhancing investment system innovation, tax relaxation and project demonstration.

\subsubsection{Increasing Support Funds, and Enhancing Investment System Innovation}

The main task of policy support is to increase funds de- votion, make corresponding measures, and resolve the source of start-up funds to form smooth investment channels. All these should be aimed at the current status of rice straw conversional power generation technology and the investment problem met in the market. The following works should be carried out by the government to support the development:

1) Setting up a special project assessment institute, providing references or sponsorship for financial institutes and promoting investment institutes participating in rice straw energy trade;

2) Setting up special funds for carrying out pilot development with an aim to drive society investment, and cultivate mature market;

3) Strengthening the collaboration between technological companies and investors for funds raising.

Currently, the main body of China's renewable energy is over single [15]. For some reasons, the domestic enterprises have not invested enough in this field. In order to formulate a long-term and effective development mechanism for rice straw to energy, we should made enormous efforts on exploring renewable energy's capital market, including enlarging the government support, strengthening the back support and bring into full play the Build-Operate-Transfer energy fund, stocks and public fund, and some other market financing methods.

\subsubsection{Tax Relaxation}

All of the agriculture energy projects, such as domestic cooking projects, are difficult to meet the economic situation in China, but yet they have their own merits and contribution in reducing pollution. In order to make these projects sustainable, the government should implement relevant policies such as to reduce the profit tax and to reduce interest rate to the loan related to the investment. These incentives can increase the profit capability and attract more investments.

Favorable taxation policy is a most universal encouragement policy in the world currently. There are some areas could find its presentation, mainly including: the value added tax for small hydropower is reduced from $6 \%$ to $3 \%$; value added tax for wind energy power generation is reduced by $50 \%$; the importation of some renewable energy power generation equipment and their parts that China is unable to produce now shall be exempted from taxation; or in some cases, the tax is reduced. The income tax of renewable energy production enterprises have been exempted by some local government, for instance, Xinjiang, Inner Mongolia, etc. All of this should be available for rice straw combustion industry.

\subsubsection{Technology Demonstration}

Rice straw combustion has much better market environ- 
ment in developing countries as compared to developed countries. However, from cost analysis, even the secondary pollution issue can be settled, rice straw collection and transportation on large-scale remains a problem that would increase cost, hence reduce its competitiveness. Therefore, under the current condition of having no special protection policy, the main users are likely those enterprises/areas where large quantities of rice straw exist with convenient collection and transportation issues. In order to fully reveal the advantages of the technology both economically and technically, it is necessary for these enterprises to demonstrate commercialization, so as to allow it to be accepted gradually. Based on this, the technology performance should be improved, and a special oriented policy of support should be put into practice to enhance the possibility of applying.

In recent years, Chinese government has implemented State Technical Problem Tackling Plan, high technology research plan, industrialized development special item and key equipment special item, etc. Through these doing, the government is to support the use of renewable energy and their parts. Besides, the government has accelerated the localization and state manufacturing process of renewable energy equipment. In all of this action, the technology demonstrations were supported by the government. After demonstration, the enterprises have laid a solid foundation for the long-term development of China's renewable energy equipment manufacturing industry.

\section{Conclusions}

As the biggest agricultural country, China has an abundant rice straw energy resource. The characteristics of typical china rice straw are presented as high moisture contents, high volatile contents, high ash contents and low bulk density. Rice straw is a major energy source in part region of China, especially in its rural areas mainly used as fuels for cooking food and/or warming room by the way of direct burning. Since 1981, China had begun to develop its biomass resources and energy conversion technology. Rice straw acts as an important role in this period. At present, rice straw was usually disposed of by open-field burning for the reason that most growers want to burn as soon as possible, if the weather permits, to allow for fall ground preparation.

From the environmental and economical reason, rice straw should be colleted and used to produce energy. Focus is on the combustion of rice straw in this paper and challenges face to china of extraction energy from rice straw is presented that include harvesting issues, process and system considerations, technical improvement and policy support.

\section{Acknowledgements}

The Project was supported by Hunan Provincial Natural Science Foundation (11JJ22029).

\section{References}

[1] "Hunan Straw Comprehensive Utilization Planning," Hunan Economic and Information Technology Commission 2010, Changsha, 2011.

[2] Z. H. Yuan. "Research and Development on Biomass Energy in China," China Biomass Development Center, 2001, Beijing.

[3] K. L. Kadam, L. H. Forrest and W. A. Jacobson, "Rice Straw as a Lignocellulosic Resource: Collection, Processing, Transportation, and Environmental Aspects," Biomass and Bioenergy, Vol. 18, No. 5, 2000, pp. 369-389. doi:10.1016/S0961-9534(00)00005-2

[4] J. Zhao, C. Fu and Z. Yang. "Integrated Process for Isolation and Complete Utilization of Rice Straw Components through Sequential Treatment," Chemical Engineering Communications, Vol. 195, No. 9, 2008, pp. 1176-1183. doi:10.1080/00986440801943750

[5] P. McKendry, "Energy Production from Biomass (Part 2): Conversion Technologies," Bioresource and Technology, Vol. 83, No. 1, 2002, pp. 47-54. doi:10.1016/S0960-8524(01)00119-5

[6] L. F. Calvo, M. Otero, B. M. Jenkins, A. Morán and A. I. García, "Heating Process Characteristics and Kinetics of rice Straw in Different Atmospheres," Fuel Processing Technology, Vol. 85, No. 4, 2004, pp. 279-291. doi:10.1016/S0378-3820(03)00202-9

[7] N. T. Oanh, B. T. Ly and D. Tipayarom, "Characterization of Particulate Matter Emission from Open Burning of Rice Straw," Atmospheric Environment, Vol. 45, No. 2, 2011, pp. 493-502. doi:10.1016/j.atmosenv.2010.09.023

[8] B. M. Jenkins, L. L. Baxter, T. R. Miles Jr. and T. R. Miles, "Combustion Properties of Biomass," Fuel Processing Technology, Vol. 54, No. 1-3, 1998, pp. 17-46. doi:10.1016/S0378-3820(97)00059-3

[9] B. M. Jenkins, J. J. Mehlschau, R. B. Williams, C. Solomon, J. Balmes, M. Kleinman and N. Smith, "Rice Straw Smoke Generation System for Controlled Human Inhalation Exposures," Aerosol Science and Technology, Vol. 37, No. 5, 2003, pp. 437-454. doi:10.1080/02786820300977

[10] G. Engling, J. Lee and Y. Tsai, "Size-Resolved Anhydrosugar Composition in Smoke Aerosol from Controlled Field Burning of Rice Straw," Aerosol Science and Technology, Vol. 43, No. 7, 2009, pp. 662-672. doi: $10.1080 / 02786820902825113$

[11] S. C. Bhattacharya., P. A. Salam, H. L. Pham and N. H. Ravindranath, "Sustainable Biomass Production for Energy in Selected Asian Countries," Biomass and Bioenergy, Vol. 25, No. 5, 2003, pp. 471-482. doi:10.1016/S0961-9534(03)00085-0

[12] C. F. Becker, B. M. Jenkins, B. C. Horsfield and J. R. 
Goss, "Attitudes of Farmers toward Using Crop Residues as Fuel," California Agriculture, Vol. 32, 2005, pp. 8-10.

[13] M. Delivand, M. Barz and S. Gheewala, "Logistics Cost Analysis of Rice Straw for Biomass Power Generation in Thailand," Energy, Vol. 36, No. 3, 2011, pp. 1435-1441. doi:10.1016/i.energy.2011.01.026

[14] P. Zhang, Y. Yang and J. Shi, "Opportunities and Challenges for Renewable Energy Policy in China," Renew- able and Sustainable Energy Reviews, Vol. 13, No. 2, 2009, pp. 439-449. doi:10.1016/j.rser.2007.11.005

[15] X. Zhang and A. Kumar, "Evaluating Renewable EnergyBased Rural Electrification Program in Western China: Emerging Problems and Possible Scenarios," Renewable and Sustainable Energy Reviews, Vol. 15 No. 1, 2011, pp. 773-779. 